\title{
Village Network Centrality in Rural Tourism Destination: A Case from Yesanpo Tourism Area, China
}

\author{
ZHANG Rui-ying1,2 (D) http://orcid.org/oooo-0oo2-6597-1495; e-mail: zry8063@163.com \\ XI Jian-chao' (D http://orcid.org/oooo-0002-9119-3180; $\$ e-mail: xijc_984@163.com \\ WANG Shou-kun' (iD http://orcid.org/oooo-0003-3683-2354; e-mail: shoukunwang1111@163.com

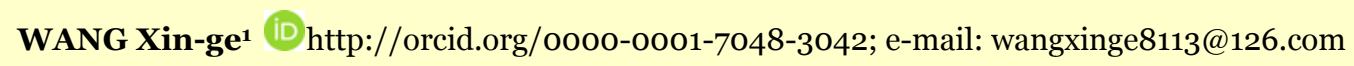 \\ GE Quan-sheng1 (i) http://orcid.org/ oooo-0oo3-0471-7220; e-mail: quanshengge123@163.com \\ 1 Institute of Geographical Sciences and Natural Resources Research, Chinese Academy of Sciences, Beijing 10o101, China \\ 2 Tianjin Agricultural University, Tianjin 300384, China
}

Citation: Zhang RY, Xi JC, Wang SK, et al. (2015) Village network centrality in rural tourism: a case from Yesanpo tourism area, China. Journal of Mountain Science 12(3). DOI: 10.1007/s11629-014-3129-7

(C) Science Press and Institute of Mountain Hazards and Environment, CAS and Springer-Verlag Berlin Heidelberg 2015

\begin{abstract}
With the development of rural tourism, the cooperation of villages has become very important. Identifying the status and importance of each village can contribute to better understanding of the integrated rural tourism management and sustainable rural tourism development. The research focused on 46 villages of Yesanpo scenic spot in China $\left(39^{\circ} 35^{\prime}-40^{\circ}\right.$ north latitude, and $115^{\circ} 16^{\prime}-115^{\circ} 30^{\prime}$ east longitude). Integrating the method of Geographical Information System (GIS) and social network analysis, the spatial centrality and interrelation of each village in Yesanpo tourism destination were evaluated. The results showed that Xinggezhuang is the spatial core village of the whole 46 villages in Yesanpo tourism areas; Xinggezhuang, Nanzhuang, Zhenchang, Daze, Liujiahe and Zishikou are sub-core villages of the six tourism spots. Magezhuang, Ximagezhuang, Eyu, Zishikou, Daze, Shangzhuang, Zhenchang and Xiazhuang should be support of the core villages, which provide subsidiary services and connects with other nodes. The results also indicated that the study of the village centrality will contribute to build an integrated hierarchy structure and to provide sufficient basis for further development of rural tourism destination.
\end{abstract}

Received: 25 July 2014

Accepted: 29 October 2014
Keywords: Network analysis; Centrality; Rural tourism; Yesanpo

\section{Introduction}

Rural tourism (RT) has been frequently taken as an alternative option, no matter in developed or developing countries, to maintain the continuous development of economy (Sang et al. 2013). It is also true with China, where a large number of rural tourism destinations have emerged since the mid1980s (Baoren 2013; Cai 2002). After 30 years development, the rural tourism attractions nationwide received and entertained about 720 million tourists in 2012, creating 34.9 billion dollars in revenue, with approximately 85,000 villages engaged throughout 31 of China's provinces and autonomous regions (China National Tourism Administration 2012). There also exist various RT spatial patterns, such as being attached to the cities (Wu et al. 2007; Rosalind et al. 2013), recreational belts around cities, scenic regions and major traffic networks, and independent tourism 
destinations (Zou 2005; Wang et al. 2012). RT has become an important driving force for rural transformation development and rural urbanization in China, especially in those remote and backward regions where tourism is the only dominant industry.

In recent ten years, China's rural tourism's research contents mainly include the basic theory of rural tourism, development mode of rural tourism, management and administration mode of rural tourism, rural tourism market, space layout of rural tourism, rural tourism's impact on local places, problems existing in the development of rural tourism and the relative solutions, etc (Lu et al. 2014; Zhang et al. 2013). This research has provided some theoretical guidelines to China's rural tourism development. However, some shortcomings still exist. Firstly, the research content mainly centers on rural tourism's concept, classification, development model, problems and solutions, with little involvement from the perspectives of psychology, sociology, folklore, geography and environmental protection. Secondly, a mature method system of rural tourism scholarship has not been built yet. Early rural tourism research has mainly depended on qualitative description, and quantitative research and mathematical models have been applied mechanically.

With the development of rural tourism, rural tourism networks gradually taking shape. Existing research shows that many tourism villages formed core-peripheral structures (Sanjay 2007). It is important to measure the complex spatialrelationship between villages for integrated rural tourism management and rural tourism sustainable development. In this study, a geographic information system (GIS) and social network analysis were employed to evaluate spatial centralities to explore the space hierarchy of villages in the rural tourism network.

Originally, the social network analysis and centrality arithmetic were applied in the social network research. At present, centrality has involved a wide range of research. It is not only confined to some traditional areas, such as city, transportation, sociology, but also constantly expand to new areas, such as emotion (Janghoon 2014), company network alliances (Turanay et al. 2014) and finance (Tolga et al. 2014). Its arithmetic has also developed continuously, evolving from simple centrality index analysis to a variety of arithmetic calculating complex centrality and centrality index (Erwan et al. 2014; Taras et al. 2014; Ahmet et al. 2014). In China, centrality research is still mainly focusing on the areas of city (Zhong 2012), transportation (Mo 2010), social network (Zheng 2010) etc., with some heuristic application and study in other areas, such as communication area (Yuan 2013), micro-traffic network (Wang 2014), etc. However, the application area tends to be more and more wide. In addition, GIS spatial analysis employed in this paper used is a method of spatial analysis and expression, with a relatively widespread application at home and abroad. It can calculate distance, analyze traffic accessibility and directly represent the spatial networks. In this paper, the author combines the centrality arithmetic and GIS methods to analyze the rural tourism network and compute the distance between villages, accessibility, with a visual expression using GIS. This combination method has been employed by Indian researcher Iger before, and the paper uses it for reference in the China's rural tourism network research.

\section{Materials and Methods}

\subsection{Study area}

Yesanpo is located in Hebei Province of China. It is in warm temperature zone with continental climate, having four distinctive seasons. It is windy in the spring, rainy in the summer, cool in the autumn and less snowy in the winter. The average temperature is $12^{\circ} \mathrm{C}$. Particularly in summer, the temperature is averagely below $30^{\circ} \mathrm{C}$ in the daytime and around $18^{\circ} \mathrm{C}$ in the nighttime, and its average temperature is $22^{\circ} \mathrm{C}$, making Yesanpo an ideal place for people to spend their summer holiday. The terrain of this region is tilted slightly from northwest to southeast. Its average altitude is $1200 \mathrm{~min}$ the northern area, $800 \mathrm{~m}$ in the southern area, and $400 \mathrm{~m}$ in the eastern area, which thus are called 'up, middle, and down' slopes. The national geological park of Yesanpo records the evolution of geological structure over the course of 3 billion years with a whole history of basement formation, 
platform development, activation of platform and tectonic movements. The national geological park of Yesanpo has significant scientific value of geology with its beautiful and exotic scenery. With combination of natural and human scenery, Yesanpo is an ideal place for tourism, vacation, and popular science.

Yesanpo tourism area is at $39^{\circ} 35^{\prime}-40^{\circ}$ north latitude, and $115^{\circ} 16^{\prime}-115^{\circ} 30^{\prime}$ east longitude. It is a popular tourist resort in northern China, $100 \mathrm{~km}$ away from Beijing, with a total area of $498.5 \mathrm{~km}^{2}$, including 6 independent tourism spots(Baili Canyon, Yesanpo ethnic culture park, Fishbone tunnel, Longmentianguan, Baicaopan and Jinhua mountains) (Figure 1). In recent years, tourism has been the leading industry in Yesanpo tourism area.

With the influx of a large number of tourists, there have been 3 towns and 46 villages being involved in rural tourism and a famous rural tourism destination has been developed. Yesanpo was designated as a five-star $(5 \mathrm{~A})$ tourism area by

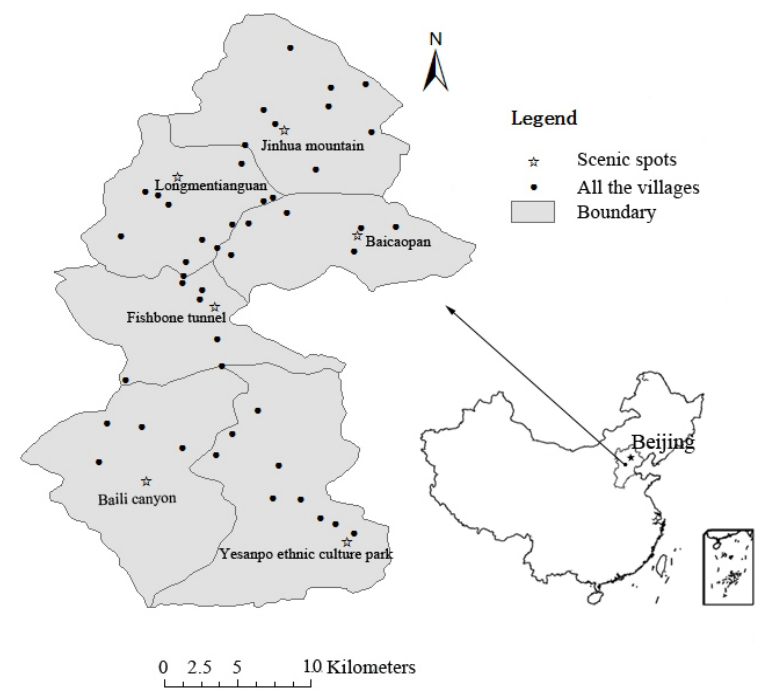

Figure 1 Location of the Yesanpo tourism area in China. the China National Tourism Administration (CNTA) in 2011. It has rich tourism resources, such as steep canyons, beautiful rivers and traditional rural culture. It is a quite popular tourist destination among Beijing citizens because of the wellpreserved eco-environment and proximity. Yesanpo received 2.24 million tourists and generated 108 million dollars in revenue in 2010. Tourism development in Yesanpo has effectively stimulated the economic activities and local employment. Types of economic activities in the villages are presented in Table 1 . These economic activities in Figure 1 are located throughout the region. However, they are practiced in varied degrees at different locations which are varied in popularity and tourist resource. In this area, tourists can explore the natural scenery, eat farm food, play drifting, watch karst cave, and have fun in a small stream. Due to difference in distances, mutual attraction, and communication and cooperation degree between each two villages in the scenic area, tourist destination and flow are very different. Some rural scenic spot has beautiful scenery, but tourists need to overcome poor transportation and information to get there.

\subsection{Methods}

\subsubsection{The centrality of rural tourism destination network}

The concept of network centrality came from mathematics graph theory and began to be applied in the middle of the twentieth century in the field of sociology. Here we study the centrality of the rural tourism destination by three centrality index.

1) Degree centrality: As defined by Freeman (1979), degree centrality is a count of the number of edges incident upon a given node (Brandes et al.

\begin{tabular}{lll}
$\begin{array}{l}\text { Table } \mathbf{1} \text { Types of economic activities in the villages in } \mathbf{2 0 1 2} \\
\begin{array}{l}\text { Tourism } \\
\text { activities }\end{array}\end{array}$ & Direct employment \\
\hline $\begin{array}{l}\text { Accommodation } \\
\text { Catering }\end{array}$ & $\begin{array}{l}\text { family inns and hotels } \\
\text { "Nongjiale " (Farmers' Home)restaurants, } \\
\text { independent restaurants and Barbecue } \\
\text { Shopping }\end{array}$ & $\begin{array}{l}\text { Building construction } \\
\text { Vegetable cultivation }\end{array}$ \\
Convenient store and tourist supplies store & $\begin{array}{l}\text { Transport, Handicraft making, production } \\
\text { of native products }\end{array}$ \\
& $\begin{array}{l}\text { Photographing, Painting from life, Horse riding, } \\
\text { Rafting, Donkey Cart, Karaoke, Video games, } \\
\text { Billiards game, Fishing, Folk performance, Go }\end{array}$ & $\begin{array}{c}\text { Horse and donkey breeding, selling of } \\
\text { entertainment equipment, installation } \\
\text { and repair of equipment, tourism sites } \\
\text { cleaning, tour guide }\end{array}$ \\
& $\begin{array}{l}\text { Kart racing, Live CS (live-action shooting game), } \\
\text { Bonfire evening, Bungee jumping }\end{array}$ & \\
\hline
\end{tabular}


2005). The degree centrality that considers spatial tourism interaction among rural villages was given by:

$$
\mathrm{C}_{\mathrm{D}}(i)=\sum_{i \neq j} S T I_{i j} /(n-1)
$$

where $C_{D}(i)$ is the degree of centrality of an individual rural village, $n$ is the total number of villages and $S T I_{i j}$ is the spatial tourism interaction between the $i_{\text {th }}$ and $j_{\text {th }}$ villages. The spatial tourism interaction based on the gravity model is given by:

$$
S T I_{i j}=T_{i} \times T_{j} \times D_{i j}
$$

where, $T$ denotes villages' tourism development level. It is determined by the proportion of the households engaged in tourism, the proportion of the population employed in tourism, and beds of family inns. $D_{i j}$ is the distance index between the $i_{t h}$ and $j_{\text {th }}$ village, which is applied as the friction factor in this model, and $\beta$ is a parameter ranging between 1.0 and 2.0 $(\beta=2$ in this article. This study selects $\beta=1, \beta=1.5$ and $\beta=2$ to conduct three analog calculations, and given consequences are similar. So the further calculation employs $\beta=2$. Just because of limited pages, consequences of all parameters are not listed in the paper.). For a tourism village, there will be a more powerful spatial tourism interaction if there are more huge proportion of the household engaged in the tourism, more beds of family inn, and higher level of tourism development.

The calculationmodel of $T$ from model (2) is given by:

$$
\mathrm{T}_{\mathrm{i}}=\left(w_{i 1} t_{i 1}+w_{i 2} t_{i 2}+w_{i 3} t_{i 3}\right)+1
$$

where $t_{i 1}$ is the standardized proportion of households engaged in the tourism, $t_{i 2}$ is the standardized proportion of the population employed in the tourism, and $t_{i 3}$ is the standardized bed of familv inn. $W$ is weight $\left(w_{i 1}=0.32, w_{i 2}=0.33, w_{i 3}=0.35\right)$ ). The standardized process is given by:

$$
t_{i}=\left(B L_{i}-B L_{\min }\right) /\left(B L_{\max }-B L_{\min }\right)+1
$$

where $B L_{i}$ the real data from research, including the proportion of the household engaged in the tourism, the proportion of the population employed in the tourism, and the total beds of the family inn owns.

The process for evaluating the distance index is similar to that for the standardized level of village's tourism and is given by:

$$
D_{i j}=\left(S P_{i j}-S P_{\min }\right) /\left(S P_{\text {max }}-S P_{\text {min }}\right)+1
$$

where, $D_{i j}$ is the distance index and $S P_{i j}$ is the distance of the shortest nath between $i$ and $i$ villages. Additionally, $S P_{\max }$ and $S P_{\min }$ are the maximum and minimum distance values among the villages in the entire network structure, respectivelv.

$t_{i 1}, t_{i 2}, t_{i 3}$ representing the standardized proportion of the households engaged in the tourism, the standardized proportion of the population employed in the tourism, and the standardized beds of family inn, respectively, are shown in Table 2. " 1 "is added to equations $3,4,5$ in order to avoid the extreme case where the zero

\begin{tabular}{|c|c|c|c|c|c|c|c|c|c|c|c|}
\hline Villages & (H) & (P) & (B) & Villages & (H) & (P) & (B) & Villages & (H) & (P) & (B) \\
\hline Lingnantai & 1.02 & 1.24 & 1.01 & Duya & 1.11 & 1.42 & 1.52 & Beibianqiao & 1.71 & 1.26 & 1.50 \\
\hline Zhuangtou & 1.02 & 1.08 & 1.01 & Fushankou & 1.07 & 1.45 & 1.07 & Nanzhuang & 1.35 & 1.14 & 1.06 \\
\hline Sandaogang & 1.03 & 1.05 & 1.01 & Gougezhuang & 1.64 & 1.53 & 1.50 & Bolincheng & 1.04 & 1.18 & 1.04 \\
\hline Daogou & 1.09 & 1 & 1.03 & Xiaofengkou & 1.02 & 1.64 & 1.01 & Xinhuang & 1.03 & 1.15 & 1.03 \\
\hline Tiejiao & 1.02 & 1.18 & 1.02 & Pengtou & 1.09 & 2 & 1.11 & Hexi & 1.04 & 1.14 & 1.04 \\
\hline Luogutai & 1.03 & 1.27 & 1.02 & Heishuisi & 1.02 & 1.32 & 1.01 & Nanbianqiao & 1.03 & 1.07 & 1.05 \\
\hline Sangyuanjian & 1.06 & 1.32 & 1.05 & Eyu & 1.02 & 1.28 & 1.02 & Xiazhuang & 1.72 & 1.48 & 1.50 \\
\hline Shannan & 1.06 & 1.52 & 1.05 & Daze & 1.02 & 1.15 & 1.10 & Nanyu & 1.04 & 1.23 & 1.04 \\
\hline Zhenchuang & 1.37 & 1.17 & 1.35 & Zhuangli & 1.01 & 1.36 & 1.01 & Luofujiao & 1.27 & 1.01 & 1.24 \\
\hline Magezhuang & 1.03 & 1.56 & 1.08 & Taiping & 1.03 & 1.28 & 1.02 & Songshukou & 1.51 & 1.09 & 1.57 \\
\hline Ximagezhuang & 1.04 & 1.33 & 1.08 & Beilongmen & 1.02 & 1.25 & 1.06 & Xinggezhuang & 1.68 & 1.07 & 1.34 \\
\hline Jiaojiekou & 1.05 & 1.28 & 1.09 & Dalongmen & 1.6 & 1.11 & 1.40 & Liujiahe & 1.7 & 1.19 & 1.60 \\
\hline Zishikou & 1.04 & 1.97 & 1.12 & Nanchanfang & 1.01 & 1.1 & 1.01 & Qingquansi & 1.01 & 1.11 & 1.05 \\
\hline Shangzhuang & 1.15 & 1.2 & 1.40 & Beichanfang & 1.02 & 1.09 & 1.02 & Nanhu & 1.02 & 1.06 & 1.02 \\
\hline Beiliuzi & 1.08 & 1 & 1.09 & Panpo & 1.01 & 1.2 & 1.03 & & & & \\
\hline Nanliuzi & 1.09 & 1.01 & 1.09 & Beiyuta & 1.03 & 1.12 & 1.01 & & & & \\
\hline
\end{tabular}
value of a factor in equation 2 could cause the entire function being zero value (or infinite value),

Table 2 Standardized indices of households engaged in the tourism (H), population employed in the tourism (P) and beds of family inn (B). 
especially where some factor becomes zero value due to rounding.

2) Betweenness centrality (Bavelas 1948; Freeman 1977): The betweenness centrality of a node depends on the extent to which it is needed as a link in the chain of contacts. The node of high betweenness centrality facilitates the spread of information within the network. In the spatial network, the betweenness centrality is the proportion of all of the geodesics between the node itself and the pairs it makes with other nodes and is given by:

$$
C_{B}(m)=\sum_{i}^{n} \sum_{j}^{n}\left(g_{i m j} / g_{i j}\right) /\{(n-1)(n-2) / 2\}
$$

where $C_{B}(m)$ is the betweenness centrality of individual mural Villosac. $n$ is tho totol numhar of villomas $g_{::}$is tha numbar of tha shortact noth between $i$ and $j$ villages, and $g_{i m j}$ is the frequency of instances in which village $m$ is located on the shortest path between $i$ and $j$ villages.

3) Eigenvector centrality (Bonacich 1987; Freeman 1978): The eigenvector centrality is a measure of the importance of a node in a network and it is based on the idea that a node is more central if it is in relation with nodes that are themselves central. It assigns relative centrality to all villages in the network based on the principle that connections to high-level centrality villages contribute more to the centrality of the village than equal connections to low-level centrality villages. In other words, the eigenvector centrality could be conducted to find the central of the whole area. In this spatial network, $\mathrm{n}$ is the total number of nodes, A is adjacentmatrix of the network. $a_{i j}=1$, if there is connection between this node and $(i, j), a_{i j}=0$ if not. $\lambda_{1}, \lambda_{2}, \ldots, \lambda_{n}$ are eigenvalues of $A$, and eigenvector of each eigenvalue is $e=\left(e_{1}, e_{2}, \ldots, e_{\mathrm{n}}\right)$, as follows: $\lambda \mathrm{e}_{\mathrm{i}}=\sum_{j=1}^{n} a_{i j} e_{j}$. Eigenvector centrality is given by:

$$
\mathrm{C}_{e}(i)=\lambda^{-1} \sum_{j=1}^{n} a_{i j} e_{j}
$$

\subsection{Data collection and processing}

Data sources contain two parts, the primary data and secondary data. The primary data comes from the field survey, through the methods of key person interviewing (KPI). All data was collected from April to June 2013.The key persons contain two or three villageleaders from each of the 46 villages. The data contains number of villages, population, the households engaged in tourism, the population employed in tourism, beds of family inns. In addition, we have geographical coordinates of 46 villages in the field by GPS positioning. The secondary data mainly comes from the local tourism management department, Yesanpo management committee, and Google Earth website, which included the locally available documents on tourism planning, published social and economic statistics and Graphicdata (including Status map of Yesanpo tourist area and remote sensing image from Google Earth).

We made vector map by geographical coordinates of 46 villages and graphicdata.Based on the fieldwork of locations determination and the indoor analysis of the vector map of the 46 villages, a spatial network structure and an adjacency matrix were constructed using the shortest paths among villages using GIS (Wang et al. 2006; Xue 2008). Then the spatial centralities (degree, betweenness, and eigenvector centrality) were calculated in the spatial network structure considering not only the connectivity but also the interaction between nodes. Connectivity has been discussed in the previous section where the adjacency matrix was constructed (If the two villages are interconnected, then the value is 1 . If not, the value is o) (Liu 2004; Bonacich 1972; Borgatti 2005). The spatial tourism interaction is represented as a network flow, which is the weight of the links in the spatial network, and it can be measured using a spatial interaction model (such as the gravity model). It is related to tourism factors such as the proportion of the household engaged in tourism, the proportion of the population employed in tourism, the number of beds for reception, and the shortest path between two villages.

\section{Results}

\subsection{Degree centrality of rural tourism network}

As shown in Table 3, Xinggezhuang, 


\begin{tabular}{|c|c|c|c|c|c|c|c|}
\hline Village & Value & Village & Value & Village & Value & Village & Value \\
\hline Xinggezhuang & 0.053 & Qingquansi & 0.028 & Beiyuta & 0.022 & Nanpo & 0.011 \\
\hline Nanzhuang & 0.046 & Nanhu & 0.028 & Sangyuanjian & 0.016 & Sandaogang & 0.011 \\
\hline zhenchang & 0.045 & Xiaofengkou & 0.027 & Heishuisi & 0.016 & Nanchanfang & 0.01 \\
\hline Zhuangli & 0.041 & Eyu & 0.027 & Xiazhuang & 0.015 & Beichanfang & 0.01 \\
\hline Luogutai & 0.039 & Ximagezhuang & 0.027 & Dalongmen & 0.015 & Beibianqiao & 0.008 \\
\hline Daze & 0.037 & Songshukou & 0.027 & Zhuantou & 0.013 & Xinghuang & 0.008 \\
\hline Liujiahe & 0.036 & Gougezhuang & 0.024 & Beiliuzi & 0.013 & Bailincheng & 0.007 \\
\hline Zishikou & 0.032 & Pengtou & 0.024 & Beilongmen & 0.013 & Nanyu & 0.007 \\
\hline Shannan & 0.031 & Jiaojiekou & 0.023 & Luofujiao & 0.013 & Dushankou & 0.005 \\
\hline Magezhuang & 0.031 & Daogou & 0.02 & Duya & 0.013 & Lingnantai & 0.002 \\
\hline Hexi & 0.030 & Shangzhuang & 0.02 & Nanbianqiao & 0.012 & & \\
\hline Tiejiao & 0.028 & Taiiping & 0.02 & Nanliuzi & 0.012 & & \\
\hline
\end{tabular}

Nanzhuang, Zhenchang, Zhuangli, Luogutai, Daze, Liujiahe, Zishikouare the high-level degree centrality villages, the highest is 0.053 , and the lowest is 0.002 . These results indicate that degree centralities of the whole 46 villages are all very low, less than 0.2. Degree centrality changes with the proportion of the household engaged in tourism, the proportion of the population employed in tourism, and beds of family inns. We can drawaconclusion from Figure 2 that villages in north have higher degree centralities than villages in west.

\subsection{Betweenness centrality of rural tourism network}

In rural tourism network, the betweenness centrality stands for the pivotal role of nodes, higher level betweenness centrality means more important in pivotal role. The betweenness centralities are shown in Table 4.

The high level betweenness centralities are calculated in Magezhuang (0.533), Ximagezhuang (0.469), Eyu(0.342), Zishikou (o.291), Dazecun (0.281), Shangzhuang (0.236), Zhenchang (0.213), Xiazhuang (0.202). These villages' betweenness centrality is above 0.2. These villages are transportation junction, where the nodes become connectivity centers and only way that must be passed (Figure 3). Villages have low level betweenness centrality to $\mathrm{O}$ are Lingnantai, Sandaogang, Daogou,Fushan, Heishuisi, Nanchanfang, Beichanfang, Panpo, Beibianqiao, Bolincheng, Xinghuang, Hexi, Nanyu. As endpoints of this network, these villages have no transit function in the rural tourism network.

\subsection{Eigenvector centrality of rural tourism network}

As shown in Table 5, villages with high-level

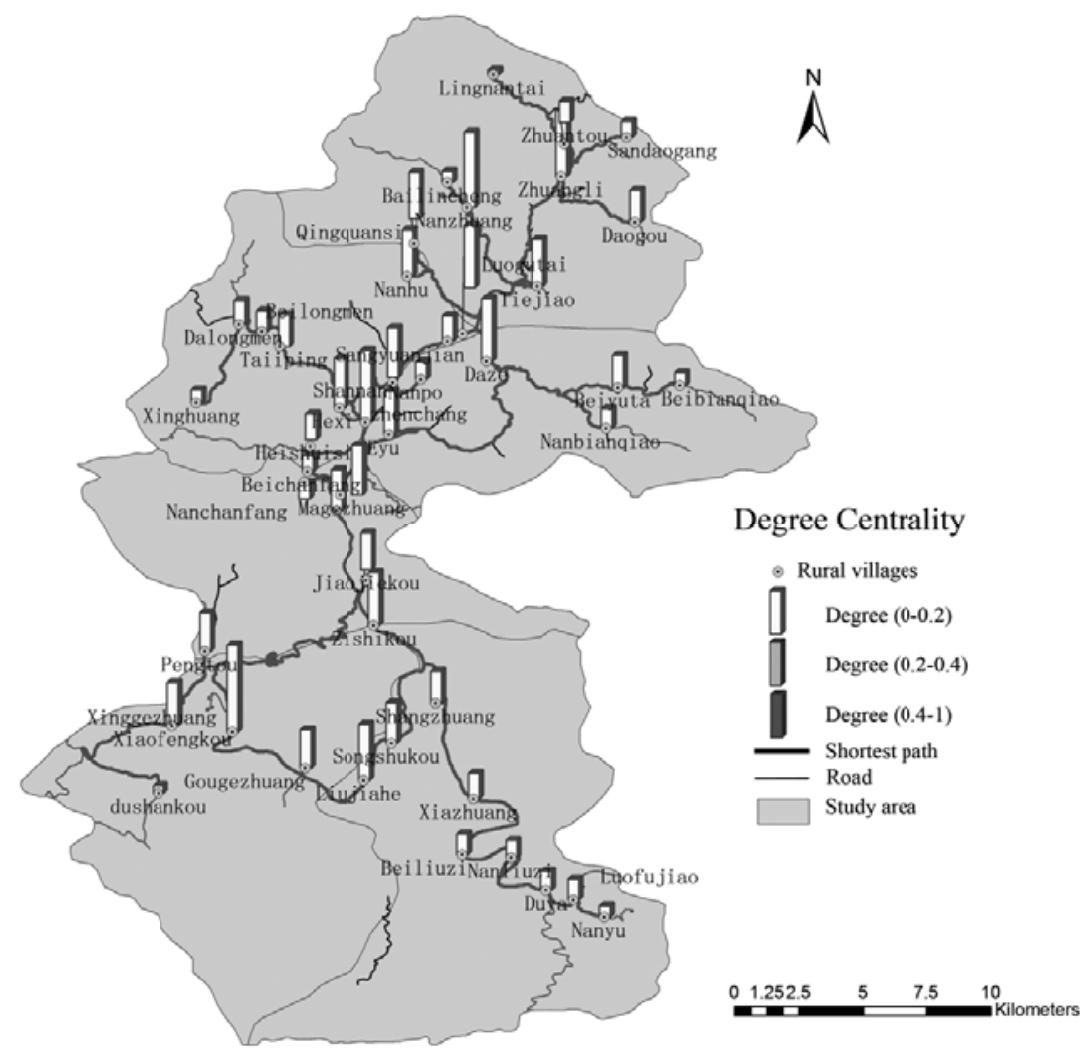

Figure 2 Results of degree centrality. 


\begin{tabular}{|c|c|c|c|c|c|c|c|}
\hline Village & Value & Village & Value & Village & Value & Village & Value \\
\hline Magezhuang & 0.533 & Xinggezhuang & 0.118 & \begin{tabular}{|l|} 
Dalongmen \\
\end{tabular} & 0.044 & Heishuisi & 0 \\
\hline Ximagezhuang & 0.469 & Shannan & 0.115 & Luofujiao & 0.044 & Nanchanfang & $\mathrm{O}$ \\
\hline Eyu & 0.342 & Beiyuta & 0.108 & Songshukou & 0.02 & Beichanfang & $\mathrm{O}$ \\
\hline Zishikou & 0.291 & Xiaofengkou & 0.094 & Gougezhuang & 0.009 & Nanpo & $\mathrm{O}$ \\
\hline Daze & 0.281 & Duya & 0.087 & Liujiahe & 0.009 & Beibianqiao & $\mathrm{O}$ \\
\hline Shangzhuang & 0.236 & Beilongmen & 0.087 & Nanhu & 0.002 & Bailincheng & o \\
\hline zhenchang & 0.213 & Luogutai & 0.077 & Lingnantai & $\mathrm{O}$ & Xinghuang & $\mathrm{O}$ \\
\hline Xiazhuang & 0.202 & Nanzhuang & 0.07 & Sandaogang & o & Hexi & o \\
\hline Zhuangli & 0.169 & Nanbianqiao & 0.063 & Daogou & o & Nanyu & o \\
\hline Beiliuzi & 0.166 & Sangyuanjian & 0.055 & Tiejiao & o & Qingquansi & $\mathrm{O}$ \\
\hline Nanliuzi & 0.127 & Jiaojiekou & 0.049 & Dushankou & o & & \\
\hline Taiiping & 0.127 & Zhuantou & 0.044 & Pengtou & o & & \\
\hline
\end{tabular}

eigenvector centralities is Xinggezhuang, Liujiahe, Gougezhuang, Zishikou, Pengtou, Xiaofengkou, Ximagezhuang, Jiaojiekou, Songshukou, Shangzhuang and Magezhuang. Xinggezhuang has the highest eigenvector centrality among the 46 villages, only Xinggezhuang and Liujiahe have eigenvector centralities above $0.4,7$ villages' eigenvector centralities are above 0.2, others' eigenvector centralities are below 0.2 (Figure 4).The eigenvector centrality considers the centrality of adjacent villages. Therefore, a village connected to high-level centrality villages could have a high-level eigenvector centrality; this means that eigenvector centrality is an index indicative of the opportunity to improve the power of influence on other villages. The eigenvector centrality is closely related to the spatial tourism interaction, which is why the eigenvector centrality was estimated differently according to the spatial tourism interaction.

\section{Conclusion and Discussion}

\subsection{Discussion}

Centrality is the focus of social network research. It shows the status and function characterization of individual or organization in the network. Research on the centrality can contribute to better understanding of the status and importance of each village in the rural tourism networks.

Different spatial centrality indexes estimated the grade function of villages in the rural tourism network. Degree centrality is a count of the number of edges incident upon a given node, high-level degree centrality indicates that it may be sub-core village. The betweenness centrality estimates the

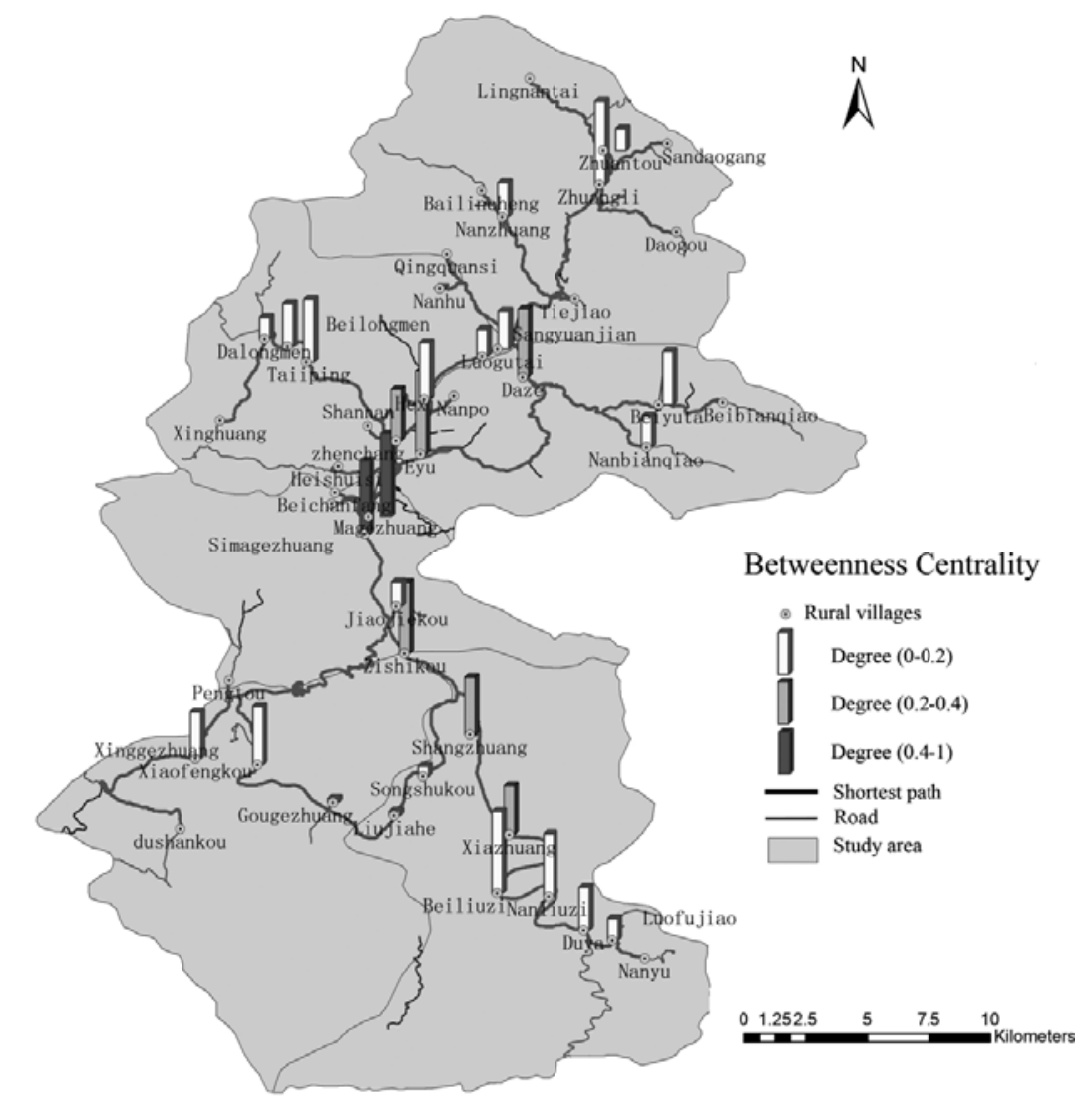

Figure 3 Results of betweenness centrality. 


\begin{tabular}{|c|c|c|c|c|c|c|c|}
\hline Village & Value & Village & Value & Village & Value & Village & Value \\
\hline Xinggezhuang & 0.531 & Daze & 0.082 & Daogou & 0.029 & Beiliuzi & 0.008 \\
\hline Liujiahe & 0.451 & Zhuangli & 0.081 & Xiazhuang & 0.027 & Beibianqiao & 0.005 \\
\hline Gougezhuang & 0.379 & Tiejiao & 0.08 & Heishuisi & 0.024 & Beilongmen & 0.004 \\
\hline Zishikou & 0.287 & Qingquansi & 0.08 & Bailincheng & 0.022 & Lingnantai & 0.002 \\
\hline Pengtou & 0.254 & Nanhu & 0.07 & Taiping & 0.021 & Nanliuzi & 0.001 \\
\hline Xiaofengkou & 0.237 & Magezhuang & 0.064 & Beiyuta & 0.020 & Dalongmen & 0.001 \\
\hline Jiaojiekou & 0.230 & Zhenchang & 0.059 & Nanbianqiao & 0.018 & Duya & o \\
\hline Songshukou & 0.23 & Sangyuanjian & 0.04 & Nanpo & 0.017 & Xinghuang & o \\
\hline Ximagezhuang & 0.227 & Shannan & 0.04 & Zhuantou & 0.015 & Nanyu & o \\
\hline Shangzhuang & 0.103 & Dushankou & 0.035 & Sandaogang & 0.013 & Luofujiao & o \\
\hline Nanzhuang & 0.103 & Eyu & 0.033 & Nanchanfang & 0.011 & & \\
\hline Luogutai & 0.09 & Hexi & 0.032 & Beichanfang & 0.010 & & \\
\hline
\end{tabular}

ability to be a pivot, high-level betweenness centrality indicates that it plays an important role in connecting other villages. The eigenvector centrality is a measure of the importance of a node in a network; high-level eigenvector centrality indicates that it may be the core village. It provides important theoretical basis to estimate spatial characteristics and development of rural tourism though the study on spatial centrality of rural tourism network.

Study on the centralities of tourism villages is able to promote the integrated rural tourism management: (1) The centrality of a certain village determines its status and importance in the rural tourism network, which can contribute to build an integrated hierarchy structure and to provide sufficient basis for further development of rural tourism destination. As shown in table 5, Xinggezhuang is the spatial core village of the whole 46 villages in Yesanpo tourism area; Xinggezhuang, Nanzhuang, Zhenchang, Daze, Liujiahe and Zishikou are sub-core villages of the six tourism spots.Magezhuang,

Ximagezhuang, Eyu, Zishikou, Daze, Shangzhuang, Zhenchang and Xiazhuang should be support of the core villages, which provide subsidiary services and connects with other nodes (Table 6). (2) It is important to improve the traffic infrastructure to support hierarchy structure of the villages, including improving the connection from the external traffic trunk to tourist areas, constructing the internal roads from the tourist attractions to the core village and from the weak to strong centrality village. By the improvement of traffic situation and the accessibility of rural tourism destination, the restriction of traffic factors on the development of rural tourism can be reduced, to promote the formation of ordered structure of tourism.

In terms of results of degree centrality and

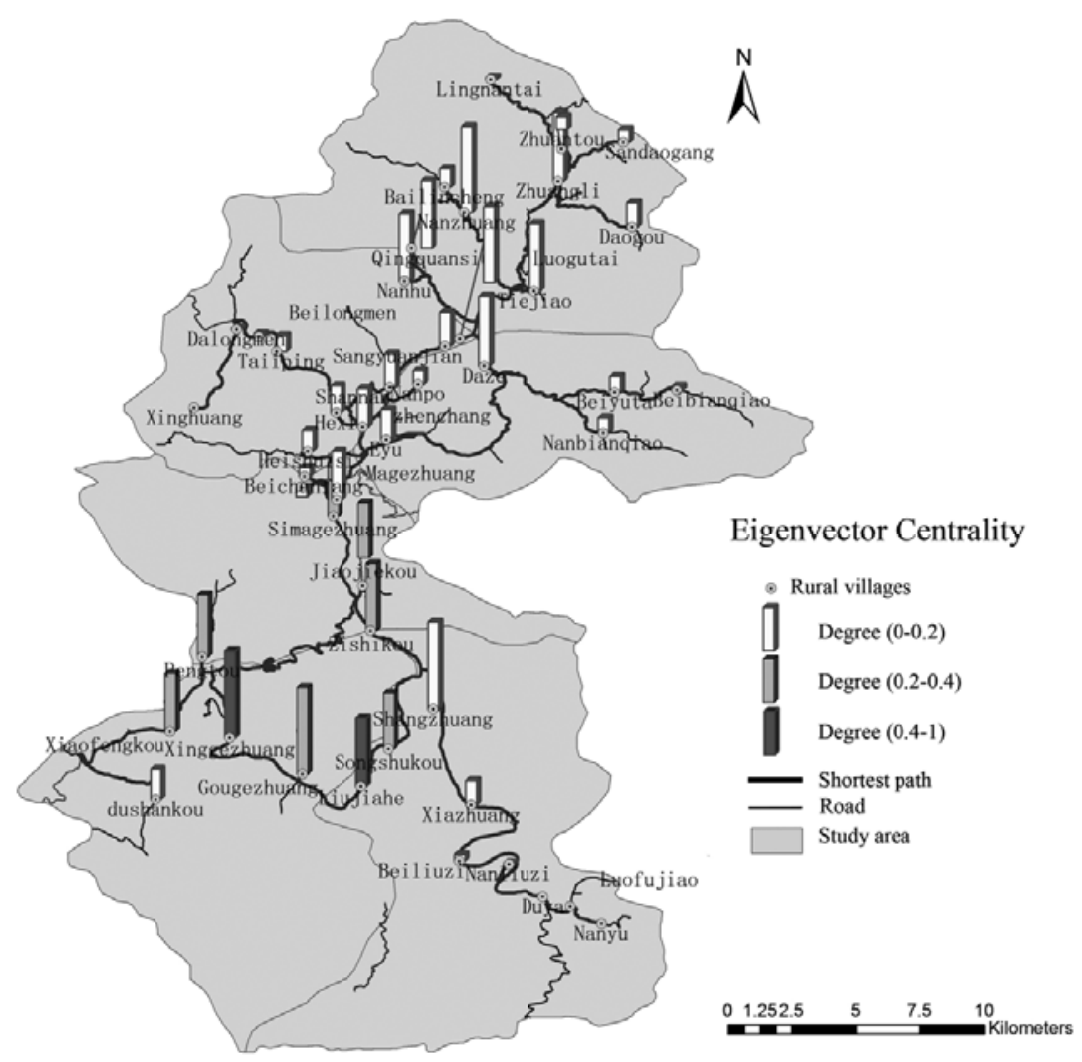

Figure 4 Results of eigenvector centrality. 


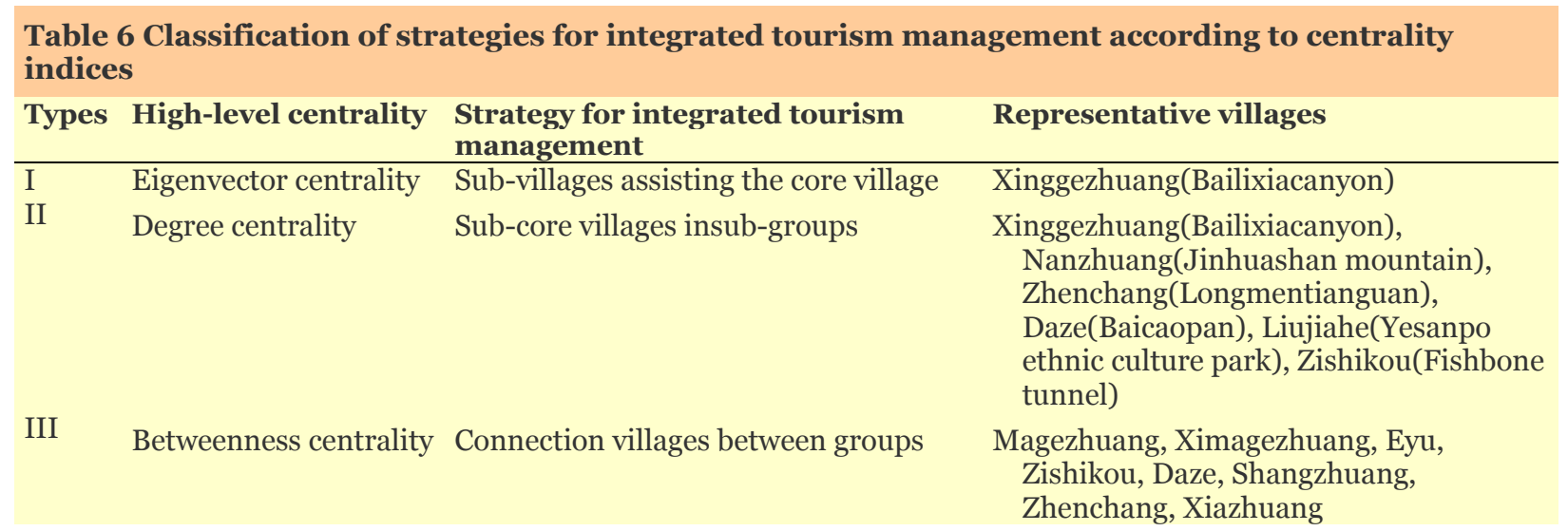

betweenness centrality study, connectivity and connection degree between north villages is obviously higher than that between south villages. In fact, north regions of Yesanpo mainly develop mountain tourism, while south regions mainly develop drifting and sightseeing projects based on their water resources. The conclusion that development of mountain tourism requires regional harmonious development will provide guidelines for north villages' future development of mountain tourism resources.

\subsection{Conclusion}

In the 21th century, rural tourism grew rapidly in Chinese rural area and its contribution and significance to local economy is obvious. The development of rural tourism has experienced the change from island model to network model. Now it's moving forward to a more advanced stage. However, the problems of fragmentation and arbitrariness appear continuously, resource and fund cannot be converged effectively, and a whole planning guideline under scientific study is needed. This paper, which is based on vector map data and data of shortest distance between villages calculated through ARCGIS tool, builds an adjacent matrix and rural space network structure, and finds out the central villages and contact-type villages through social network centrality calculation, has an important guiding significance to rural tourism development. First, it's very useful in evaluating overall space features of tourist region and determining development strategy of overall space, in addition, it could help identify core village and determine the development subsequence; Second, it is important to improve the traffic infrastructure to support hierarchy structure of the villages, including improving the connection from the external traffic trunk to tourist areas, constructing the internal roads from the tourist attractions to the core village and from the weak to strong centrality village. By the improvement of traffic situation and the accessibility of rural tourism destination, the restriction of traffic factors on the development of rural tourism can be reduced to promote the formation of ordered structure of tourism.

And of course, this centrality calculation of rural tourist area has a few limitations, and could not fully reflect village's position and function. Because the calculation only selectively considers three attribute factors of village itself, without consideration of village's resource endowment, accessibility to roads, seasonality, and tourist preference, etc. The author will attempt to consider these factors in future study to fully analyze rural tourism centrality.

\section{Acknowledgments}

This research was supported by the Humanities and Social Science Research Foundation Project of Tianjin Higher Colleges and Universities (No. 20142112). The authors would like to thank participating colleagues and farmers for their assistance and cooperation during the survey. 


\section{References}

Sang HL, Choi JY, Yoo SH, et al.(2013) Evaluating spatial centrality for integrated tourism management in rural areas using GIS and network analysis. Tourism Management 34: 14-24. DOI:10.1016/j.tourman.2012.03.005

Baoren S (2011)Rural tourism in China. Tourism Management 2(6): 1438-1441. DOI: 10.1016/j.tourman.2010.12.005.

Cai L (2002) Cooperative branding for rural destinations. Annals of Tourism Research 29(3): 720-742. DOI: 10.1016/ S0160-7383(01)00080-9

$\mathrm{Wu} \mathrm{BH}, \mathrm{Wu} \mathrm{J}$ (2007) Industrial Upgrading of Rural Tourism Development in China. Tourism Science 21(3): 11-14. (In Chinese) DOI: 10.3969/j.issn.1006-575X.2007.03.004

Rosalind SJL, Wu BH, Jinah P, et al. (2013) Women's role in sustaining villages and rural tourism in China. Annals of Tourism Research 10(43): 634-638. DOI: 10.1016/j.annals. 2013.07.009

Zou TQ (2005) On the Development Pattern of Rural Tourism in China- Comparative Studies on the Development between the Happy-farmer in Chengdu and the Folklore-hamlet in Beijing. Tourism Tribune 3: 63-68. (In Chinese).

Wang X, Huang SS, Zou TQ, et al. (2012) Effects of the high speed rail network on China's regional tourism development. Tourism Management 1(1): 34-38. DOI: 10.1016/j.tmp.2011. 10.001

Lu XL, Cheng YH, Wang LW (2014) 20 Years of Rural Tourism. Resources Science 36(1): 200-205. (In Chinese)

Zhang Y, Yang XX (2013) Rural Tourism Literatures Reviewed of Domestic Geography and Tourism Journals in Recent Years. Journal of Southwest Agricultural University (Social Science Edition) 11(9): 2-7. (In Chinese)

Sanjay K (2007) Tourism and rural settlements Nepal's Annapurna region. Annals of Tourism Research 34(4): 855875. DOI:10.1016/j.annals.2007.03.012

Janghoon Y (2014) Study on emotion spaces with centrality measure. New Ideas in Psychology 35(10): 11-17. DOI: 10.1016/j.newideapsych.2014.06.001.

Erwan LM, Nicolas LS, Gilles T(2014) Heuristical top-k: fast estimation of centralities in complex networks. Information Processing Letters 114(8): 432-436. DOI: 10.1016/j.ipl.2014. 03.006

Taras A, Jose LO, Leandro T, et al.(2014) A new betweenness centrality measure based on an algorithm for ranking the nodes of a network. Applied Mathematics and Computation 244(1): 467-478. DOI: 10.1016/j.amc.2014.07.026

Ahmet ES, Erik S, Kamer K, et al. (2014)Regularizing graph centrality computations. Journal of Parallel and Distributed Computing 7: 1-7. DOI: 10.1016/j.jpdc.2014.07.006

Tolga UK, Inci Ö, Burak S (2014) Network centrality measures and systemic risk: An application to the Turkish financial crisis. Physica A: Statistical Mechanics and its Applications
405(1): 203-215. DOI: 10.1016/j.physa.2014.03.006

Turanay C, Jing S, John E(2014)When a firm's centrality in $\mathrm{R} \& \mathrm{D}$ alliance network is (not) the answer for invention: The interaction of centrality, inward and outward knowledge transfer. Journal of Engineering and Technology Management 33(3): 193-209. DOI: 10.1016/j.jengtecman. 2014.07.001

Wang FH, Chen C, Xiu CL, Zhang PY (2014)Location analysis of retail stores in Changchun, China: A street centrality perspective. Cities 41: 54-63. (In Chinese). DOI: 10.1016/ j.cities.2014.05.005

Mo HH, Jin FJ, Liu Y, et al. (2010) Network Analysison Centrality of Airport System. Scientia Geograph 30(2):204212. (In Chinese). DOI: $10.11820 /$ dlkxjz.2008.06.016

Zhong K, Xiao Y, Xu J, et al. (2012) Measuring city centralities based on the train network of china. Journal of Geoinformation Science 14(1): 85-93. (In Chinese). DOI: 10.3724/ SP.J.1047.2012.00085

Zheng DP, Dang XH (2010) Research on measurement of centrality of technological innovation network based on social network analysis - improvement of bonacich centrality. Journal of Systems \& Management 19(4): 415-427.

Yuan WG, Liu Y, Cheng JJ, et al. (2013) Empirical analysis of microblog centrality and spread influence based on Bidirectional connection. Acta Physica Sinica 62(3):1-10. DOI: 10.7498/aps.62.038901

Brandes U, Erlebach T (2005)Network Analysis: Methodological Foundations. Springer-Verlage, Berlin, Germany.

Bavelas A (1948) Amathematical model for group structure. Human Organization 7: 16-30.

Freeman LC (1977) A set of measures of centrality based on betweenness. Sociometry 40 (1): 35-41.

Bonacich PB (1987) Power and Centrality: a Family of Measures. American Journal of Sociology 92(5): 1170-1182.

Freeman LC (1978)Centrality in social networks: conceptual clarification. Social Networks 1: 215-239.

Wang JE, Jin FJ, Sun W, et al. (2006) Research on spatial distribution and service level of Chinese airport system. Journal of Geographical Sciences 61(8): 829-838. (In Chinese). DOI: 10.3321/j.issn:0375-5444.2006.08.005

Xue W (2008) Statistical analysis and the Application of SPSS. Beijing, China. (In Chinese). pp 257-269.

Liu J (2004) Introduction to Social Network Analysis. Social Sciences Academic Press, Beijing, China. pp 116-135.

Bonacich P (1972) Factoring and weighting approaches to status scores and clique identification. Journal of Mathematical Sociology 2: 113-120.

Borgatti SP (2005) Centrality and network flow. Social Networks 27: 55-71. DOI: 10.1016/j.socnet.2004.11.008 